NASA Technical Memorandum 100821

AIAA-88-2475

\title{
Mast Material Test Program (MAMATEP)
}

Michael L. Ciancone and Sharon K. Rutledge

Lewis Research Center

Cleveland, Ohio

(HASA-TH-100821) MAST MATERIAL TEST PROGRAM
(AAAATEP) (NASA) $13 \mathrm{p}$

N 88- 19592

onclas

G3/24 0130096

Prepared for

Issues of the International Space Station

sponsored by the American Institute of Aeronautics and Astronautics

Williamsburg, Virginia, April 21-22, 1988 


\section{MAST MATERIAL TEST PROGRAM (MAMATEP)}

Michael L. Ciancone and Sharon K. Rutledge

National Aeronautics and Space Administration

Lewis Research Center

Cleveland, Ohio 44135

\section{SUMMARY}

This paper discusses the Mast Material Test Program (MAMATEP) at NASA Lewis Research Center (NASA Lewis). The objectives of MAMATEP include verifying the need for, and evaluating the performance of, various protection techniques for the Solar Array Assembly mast of the Space Station Photovoltaic Power Module.

Mast material samples were evaluated in terms of mass and bending modulus, measured before and after environmental exposure. Test environments included atomic-oxygen exposure (RF plasma asher), thermal cycling, and mechanical flexing. Protective coatings included CV-l144 silicone (MCGHAN NUSIL), a Ni/Au/InSn eutectic (Composite Optics, Inc.), and an open-weave, Al braid (AEC-Able Engineering Co.).

Results indicate that unprotected samples degrade in an atomic oxygen environment at a steady rate. Open-weave, Al braid offers little protection for the fiberglass-epoxy sample in an asher environment. CV-l144 silicone offers some initial protection in an asher environment. Ni/Au/InSn eutectic offers excellent protection in an asher environment prior to thermal cycling and mechanical flexing.

Long-duration asher results from unprotected samples indicate that, even though the fiberglass-epoxy degrades, a protection technique may not be necessary to ensure structural integrity. However, a protection technique may be desirable to limit or contain the amount of debris generated by the degradation of the fiberglass-epoxy.

\section{INTRODUCTION}

NASA Lewis Research Center is responsible for the Space Station electrical power system (Work Package 4). The major hardware elements of the electrical power system are the solar dynamic power module, the power management and distribution system, and the photovoltaic (PV) power module (refs. I to 3 ).

Each PV power module, which will supply power to the space station, includes an energy storage system, a thermal control system, and two solar array assemblies. Figure 1 illustrates the location of the solar array assembly (SAA) mast within the Work Package 4 organization. Each SAA, depicted in figure 2 , is composed of two solar array blankets, two blanket boxes, and a mast and associated deployment canister. The concept of a flexible SAA deployed using a continuous-longeron mast was demonstrated by the OAST-1 experiment (also known as the Solar Array Flight Experiment (SAFE)) flown aboard STS 41-D in September 1984 (ref. 4). A more detailed description of the Space Station SAA design can be found in reference 5 . 
Figure 3 illustrates salient features of the SAA mast. The mast is used for the on-orbit deployment of the SAA blankets from the blanket boxes. In addition, it provides structural support to the extended blanket pair. Three fiberglass-epoxy structural elements (longerons), that run the length of the mast, provide a high stiffness-to-mass ratio and enable the mast to be compactly stored in the deployment canister. The longerons provide bending stiffness and strength to the mast. Fiberglass-epoxy battens and stainless steel (aircraft cable) diagonals are located at regular intervals along the length of the mast. They provide shear and torsional stiffness and strength to the mast.

Since most organics and some metals degrade in an atomic-oxygen ( $A O$ ) environment (ref. 6), a considerable amount of effort has gone into the development of a viable means for protecting the Kapton( $R$ ) substrate used in the construction of the SAA blankets (ref. 7). The Mast Material Test Program (MAMATEP) complements this effort by investigating the need for protecting the fiberglass-epoxy elements of the SAA mast structure in the low-Earth orbital (LEO) environment.

The objectives of MAMATEP are to ascertain the need for protecting the mast material, and to identify and evaluate viable mast material protection techniques. Coated and uncoated samples are subjected to an environmental testing sequence and evaluated, before and after testing, in terms of mass and bending modulus.

The requirements for the mast protection material are, in general, typical of requirements for other space Station materials. The material must be durable in the LEO environment, which includes $A O$, ultra-violet (uv) radiation, micrometeoroids, debris, and thermal cycling (ref. 8). However, because the mast is a flexing element, a protective coating applicable to rigid structures may not be appropriate for protecting the mast material, as the protective coating may be unable to withstand the high-strain environment associated with mast deployment and retraction.

\section{SAMPLE DESCRIPTIONS}

The mast material evaluated was S2-glass/epoxy. The epoxy content of each sample was reported to be 19 to 22 percent by volume. Three types of uncoated test samples, illustrated in figure 4 , were used:

Type I - Rectangular cross-section ( 0.21 by 0.41 in.) produced by AEC-Able Engineering Co. using a pre-preg roving.

Type II - Square cross-section ( 0.25 by 0.25 in.) produced by AEC-Able Engineering Co. using a pre-preg roving. Sample was formed over a mandrel surface to impart an axial radius-of-curvature of $20 \mathrm{in.}$

Type III - Quasi-square cross-section 10.25 by 0.29 in. with corners rounded to a radius-of-curvature of 0.1 in.) protruded by Airlogistics.

Each of the samples was about 5 in. long. This length was selected because it was long enough for flexing and obtaining bending modulus measurements, and short enough to fit in the air-plasma asher. 
The type of epoxy used in the production of each sample type varied. However, early test results indicated that there was little variation in the steady-state degradation rate among the sample types.

Figure 4 includes samples that were protected with the following materials: Open-weave Al braid (AEC-Able Engineering Co.), Ni/Au/InSn eutectic (Composite Optics, Inc.), and CV-1144 silicone (MCGHAN NUSIL).

These coatings were selected for evaluation based on their availability and potential durability in the low-Earth orbital environment.

The Al braid concept was developed by AEC-Able Engineering to provide a conductive path along the length of a deployable, continuous-longeron mast. The Al fibers of the braid are woven around the longeron after the roller-lug assemblies have been bonded into place on the longeron.

The Composite Optics eutectic material was developed for application to dimensionally-stable space structures. It consists of a plating primer $(0.5 \mathrm{mils})$, a plated layer of electroless nickel ( $0.3 \mathrm{mils})$, an immersion coating of gold, and a top layer of indium-tin 50-50 eutectic (Indalloy). This combination of materials, when applied to rigid space structures, provides stability by minimizing outgassing of the protected substrate while maintaining a low coefficient-of-thermal-expansion (CTE).

CV-1144 is a silicone designed for applications requiring low-outgassing and low volatile condensables under extreme operating conditions. It has the desirable characteristics of initial flexibility and ease of application.

\section{TEST PROGRAM}

\section{Long-Duration Ashing}

In order to ascertain the need for a mast material protective coating, two type-III samples were exposed for $1747 \mathrm{hr}$ in a $13.56 \mathrm{MHz}$ RF air-plasma asher. This was done to determine if the anticipated rate of epoxy loss, due to AO degradation, would decrease once most of the epoxy was removed from the surface of the sample.

The mass of the samples was measured periodically during the course of the long-duration test. A post-exposure bending modulus measurement was made and compared with the baseline bending modulus value obtained from 20 unexposed samples from the same production batch.

\section{Evaluation of Protection Techniques}

Figure 5 outlines the typical test sequence for evaulating sample protection techniques.

Task I - Dehydration and rehydration. - Task I involved the dehydration and rehydration of both protected and unprotected fiberglass-epoxy samples. The purpose of this task was to establish a baseline mass that could be duplicated for purposes of accurate mass loss determinations during task II. Many 
materials absorb water from the atmosphere. The amount of water absorbed depends greatly on the environmental humidity. If a material can be fully dehydrated and then weighed, the error due to water uptake can be eliminated. It is not always possible to perform in-situ mass measurements, so an accurate determination of the time needed to dehydrate a particular sample, and how quickly it absorbs water upon removal from vacuum, is needed.

Dehydration was performed in the quartz vacuum chamber of an air-plasma asher. Typical pressure readings during dehydration ranged form 30 to $70 \mu \mathrm{m}$. Samples were weighed before being placed under vacuum and at selected time intervals thereafter. To weigh the samples, they were quickly removed from vacuum, weighed, and returned (within $3 \mathrm{~min}$ of removal from vacuum). Dehydration generally occurred in approximately 5 days for most samples. To determine the rehydration rate, samples were removed from vacuum and periodically weighed to determine the rate of rehydration. In general, samples could be removed from vacuum for $5 \mathrm{~min}$ with minimal mass error. More detailed results are presented in reference 9 .

Task II - Air-plasma ashing. - Task II involved exposing samples to an atomic-oxygen environment created by the RF dissociation of air at $13.56 \mathrm{MHz}$ in a plasma asher (SPI Plasma Prep II). Typical pressures in the asher during testing ranged from 50 to $120 \mu \mathrm{m}$. Although the oxygen in the plasma is at various levels of ionization, and has a lower energy and a higher flux than that which occurs in low-Earth orbit, the asher is a good qualitative measure of material durability. Past experience has indicated that materials surviving asher exposure will likely also survive exposure in low-Earth orbit.

Task III - Thermal cycling. - Task III involved thermal cycling the samples to determine if the variation in temperature that will occur on-orbit (as the Space Station moves from sunlight into the shadow of the Earth and back again every $96 \mathrm{~min}$ ) will prove detrimental to the mast material protection techniques. Failure could occur in the form of cracking due to thermal expansion differences, or a loss in adhesion of the coating, either of which would allow atomic-oxygen to reach the underlying fiberglass-epoxy.

Thermal cycling was performed in a nitrogen environment at atmospheric pressure. Samples were cycled between a chamber filled with cold nitrogen gas and a chamber with heating coils. A thermocouple embedded in the center of one sample was used to determine the sample temperature so that when the desired temperature had been achieved, the samples could be cycled into the other chamber. Samples were cycled between $80^{\circ} \mathrm{C}$. and $-80^{\circ} \mathrm{C}$. for 413 cycles. The samples typically spent an average of $4 \mathrm{~min}$ in each chamber.

Task IV - Mechanical flexing. - Task IV involved flexing the samples to simulate the extension and retraction of the mast from the canister. This test was performed to determine if flexing would induce failure sites in the protective coatings. Testing was performed by repeatedly ( 100 times) bending the samples, using stainless steel clamping fixtures, to the radius-of-curvature that longerons would experience while stowed in the canister. This flexing resulted in a bending strain of 1 to 1.5 percent at the edge of the sample.

Bending Modulus Measurement. - Bending modulus measurements were made of each sample, before and after the test sequence, using a 3-point bend test (ASTM D 790-81). Although the 3-point bend test typically results in a low 
estimation of modulus (since it neglects shear deformation), it is acceptable for our purposes since we are looking for changes in modulus, rather than an accurate modulus value. The changes are observed directly from the slope of the load-deflection curve. This slope value is proportional to the bending modulus (E), and hence to the bending stiffness (EI). Thus, a change in the slope value would be representative of a change in the modulus and the bending stiffness. Measurements were made in the linear portion of the load-deflection curve. Samples that were tested to failure indicated that the typical testload range did not exceed 35 percent of the load to failure.

\section{RESULTS AND CONCLUSIONS}

\section{Long-Duration Ashing}

The first objective was to ascertain the need for protecting the SAA mast material (fiberglass-epoxy). Two unprotected samples were subjected to $1747 \mathrm{hr}$ in the asher environment. Figure 6 illustrates both an ashed sample and an unashed control sample.

Figure 7 illustrates the standardized mass loss curves for the two samples. Post-exposure sample mass measurements indicated a total mass loss of about 2 percent.

Figure 8 illustrates the load-deflection curves for a single, longduration ashed sample, and the average of 20 control samples. The ashed sample was subjected to the load sequence a number of times in order to reduce the measurement variance since only two samples were available. The larger number of control samples subjected to the load sequence reduced the sampleto-sample variance. The control samples were taken from the same batch as the ashed samples. The results indicated that the ashed sample lost 8 percent of its bending modulus, relative to the control samples.

The asher exposure time of $1747 \mathrm{hr}$ corresponds to about 67 years in LEO. Thus, the loss of bending modulus, when derated over the 15-year design life of the SAA, corresponds to a loss of less than 2 percent. Based on these results, a protection technique may not be necessary for maintaining the structural properties of the mast. However, another factor that needs to be considered before eliminating the need for a mast protective coating is the potential for contamination resulting from the debris that may result from the degradation of the mast material. A protective coating for the mast may help to contain or reduce the loss of mast material, particularly glass fibers.

\section{Evaluation of Protection Techniques}

The second objective was to identify and evaluate protection techniques for the SAA mast material (fiberglass-epoxy). Samples protected with an openweave, Al braid; $\mathrm{CV}-1144$ silicone; and, $\mathrm{Ni} / \mathrm{Au} / \mathrm{InSn}$ eutectic were subjected to dehydration, air-plasma ashing, thermal cycling, and mechanical flexing.

The open-weave, Al braid offered little protection from the asher environment. The CV-l144 silicone offered some initial protection from the asher environment. The Ni/Au/InSn eutectic offered the best protection during air- 
plasma ashing, prior to thermal cycling and mechanical flexing. More detailed test information is provided in reference 9.

Based on the results from the long-duration ashing, a protective coating may not be necessary to ensure structural durability, but it may be necessary to contain degradation products, such as glass fibers. Therefore, the coating may not need to prevent epoxy loss, so long as it contains exposed glass fibers and prevents them from separating from the mast during mast extension/ retraction or during handing.

\section{ACKNOWLEDGMENTS}

The authors wish to acknowledge the following individuals and companies for their assistance and cooperation:

Ms. Joyce Brady and Mr. Phil Paulsen of NASA Lewis for performing much of the testing in conjunction with Mr. Bruce Banks and Mr. Russ Hart.

Dr. Ken Bowles of NASA Lewis for his time and expertise in measuring bending modulus of the samples.

Mr. John Marks of Composite Optics Inc (San Diego, CA) and Mr. Max Benton of AEC-Able Engineering Co. (Goleta, CA) for providing samples for testing, with the cooperation of individuals from the Lockheed Missiles \& Space Co.

\section{REFERENCES}

1. Nored, D.L. and Bernatowicz, D.T., "Electrical Power System Design for the U.S. Space Station", NASA TM-88824.

2. Baraona, C.R., "The Space Station Power System", NASA TM 88847.

3. Tatro, C.A., "Photovoltaic Power Modules for NASA's Manned Space Station", NASA TM-10029.

4. "Solar Array Flight Experiment", Final Report, Lockheed Missiles and Space Co., LMSC-F087173, Apr. 1986.

5. "Power System Description Document (PSDD)," Internal Document, Space Station Systems Directorate, NASA Lewis Research Center, Cleveland, $\mathrm{OH}$, Sept. $11,1987$.

6. Leger, L.J., Visentine, J.T., and Schliesing, J.A., "A Consideration of Atomic Oxygen Interaction with Space Station", AIAA Paper 85-0476, AIAA 23rd Aerospace Sciences Meeting, Reno NV, 14-17 Jan 1985.

7. Photovoltaic Array Environmental Protection (PAEP) Program, Private communication with B. Sater, program monitor for NAS3-25079.

8. Smith, R.E. and West, G.S., "Space and Planetary Environment Criteria Guidelines for Use in Space Vehicle Development, 1982 Revision (Volume 1)", NASA TM-82478. 
9. Rutledge, S. and Ciancone, M., NASA Lewis research Center; Paulsen, P. and Brady, J., Cleveland State University; "Oxidation and Protection of

Fiberglass-Epoxy Composite Masts for Photovoltaic Arrays in the Low Earth Orbital Environment". Presented at the Materials Research Society Spring Meeting, Reno, NV, Apr. 5-8, 1988.

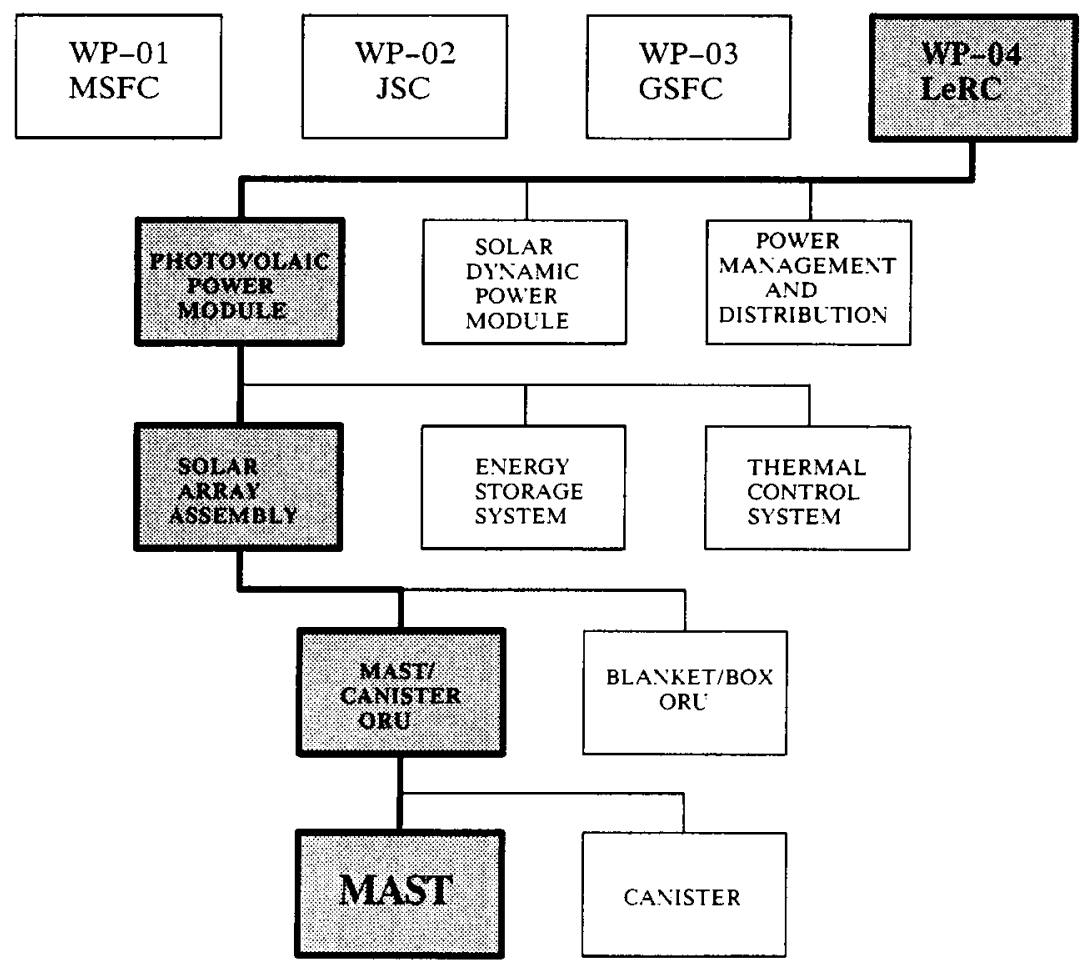

FIGURE 1. - LOCATION OF MAST WITHIN WP-04 PROGRAM. 


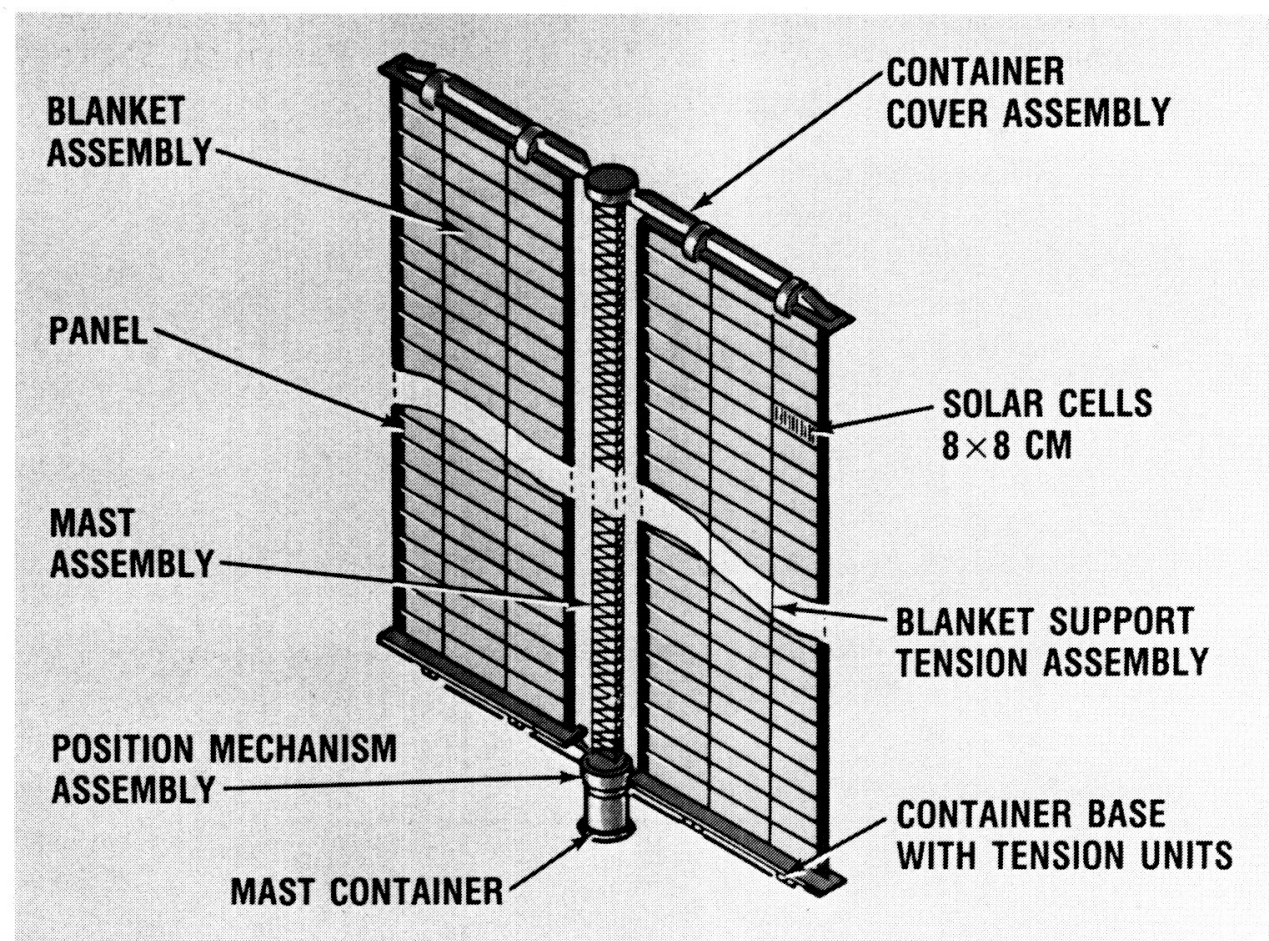

FIGURE 2. - SOLAR ARRAY ASSEMBLY.
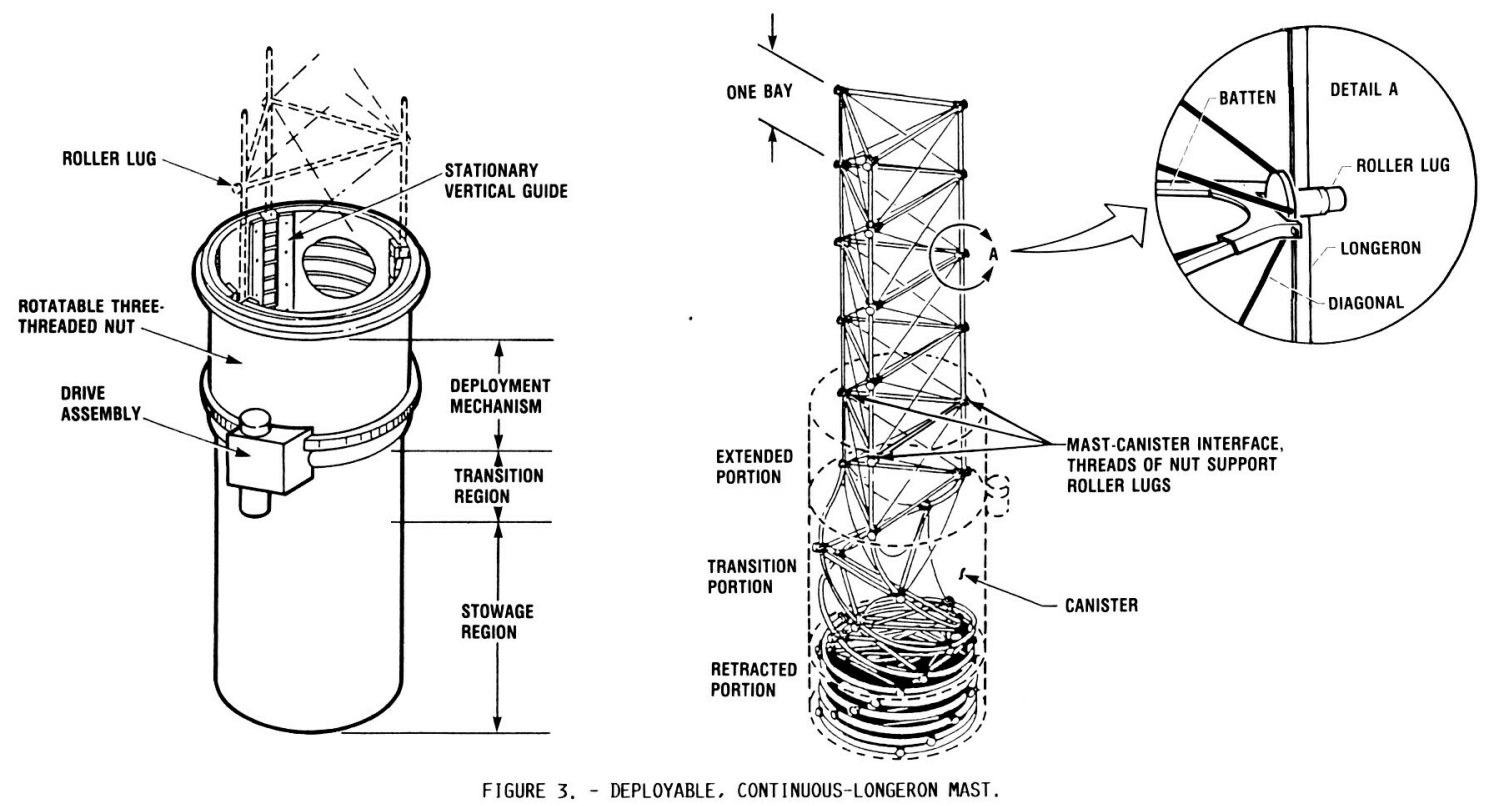

ORIGINAL PAGE IS OF POOR QUALITY 
ORIGINAL PAGE IS

OF. POOR QUALITY.

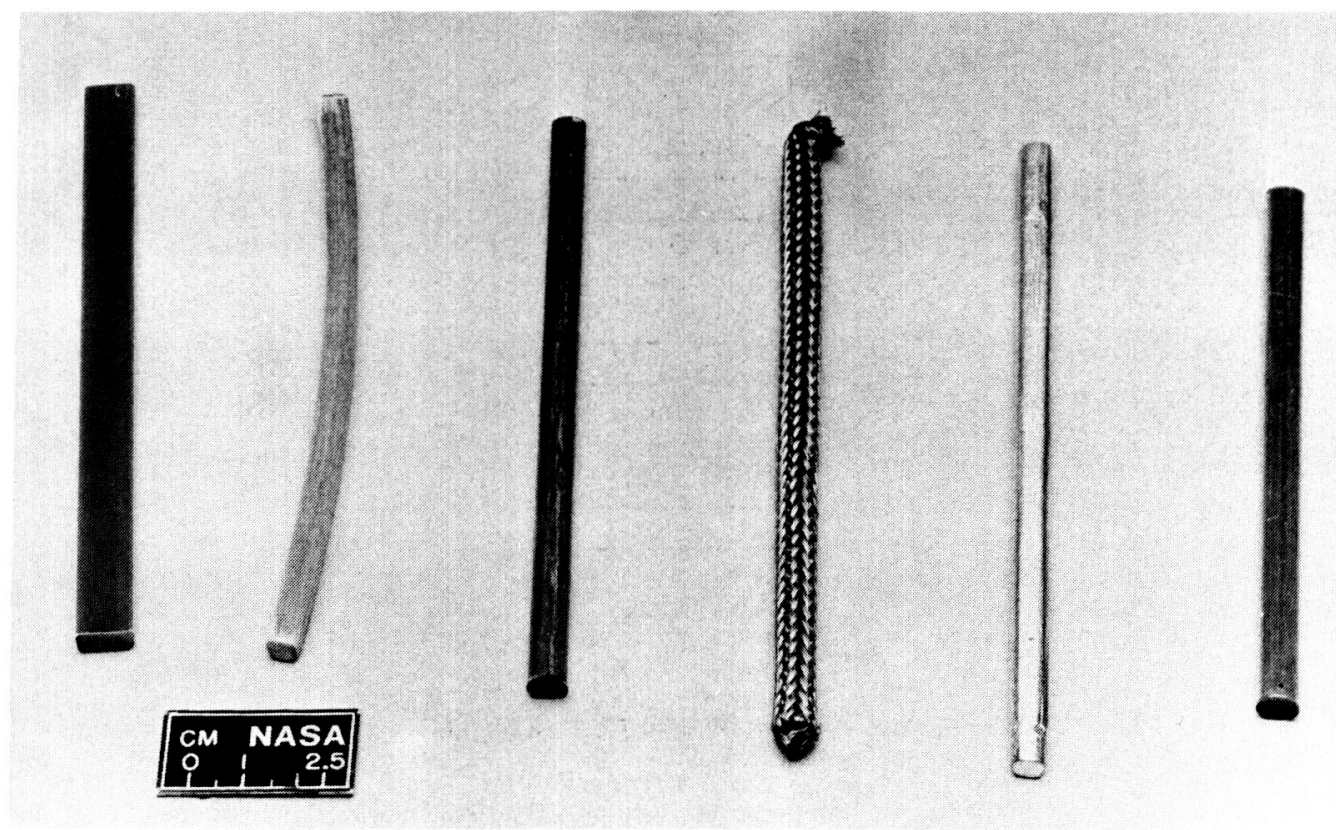

FIGURE 4. - MAST MATERIAL SAMPLES ( $L$ TO R): UNCOATED (TYPE I, TYPE II, AND TYPE III) AND COATED (AI BRAID, COI EUTECTIC, AND (V-1144 SILICONE). 


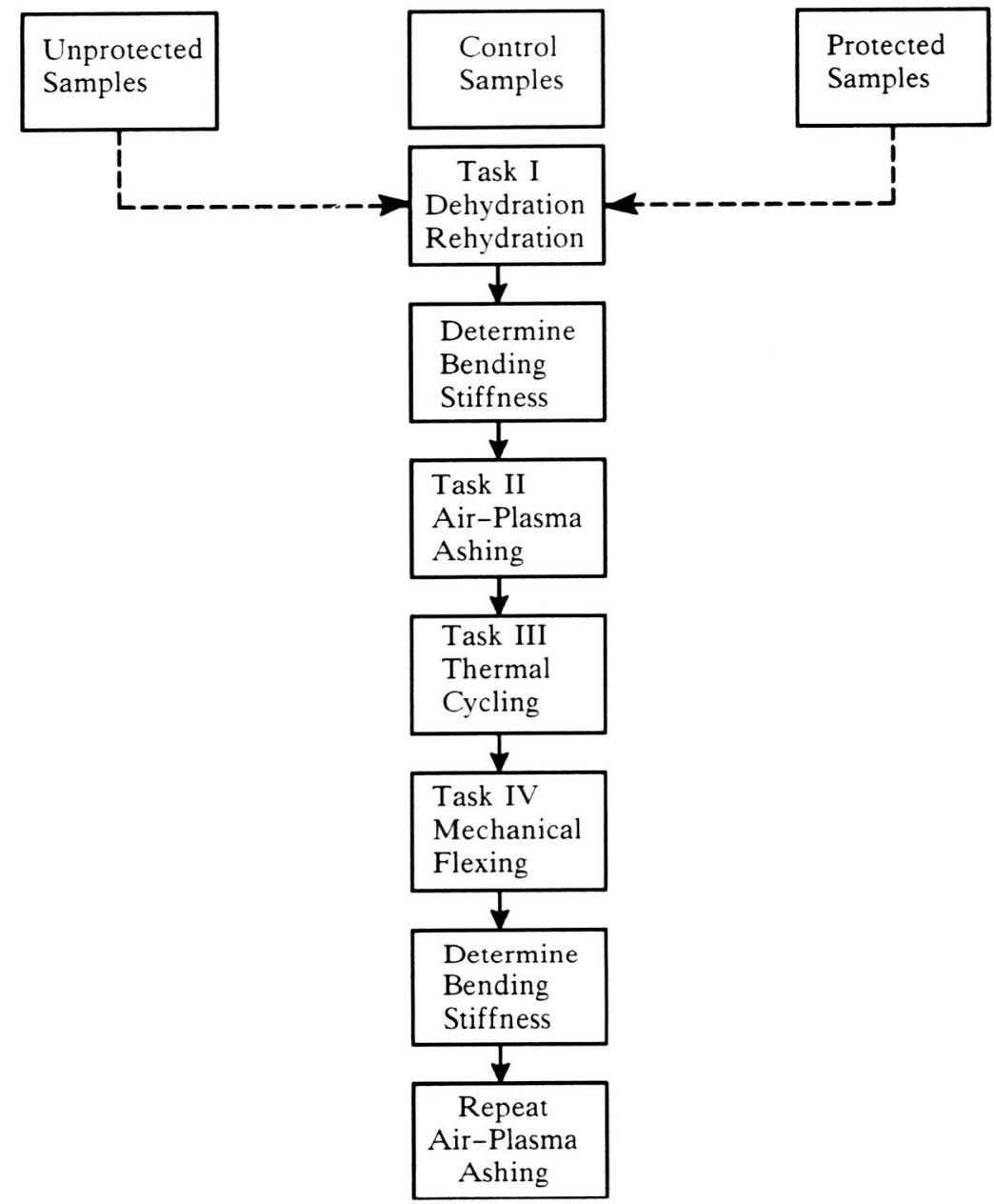

FIGURE 5. - MAMATEP TEST SEQUENCE.

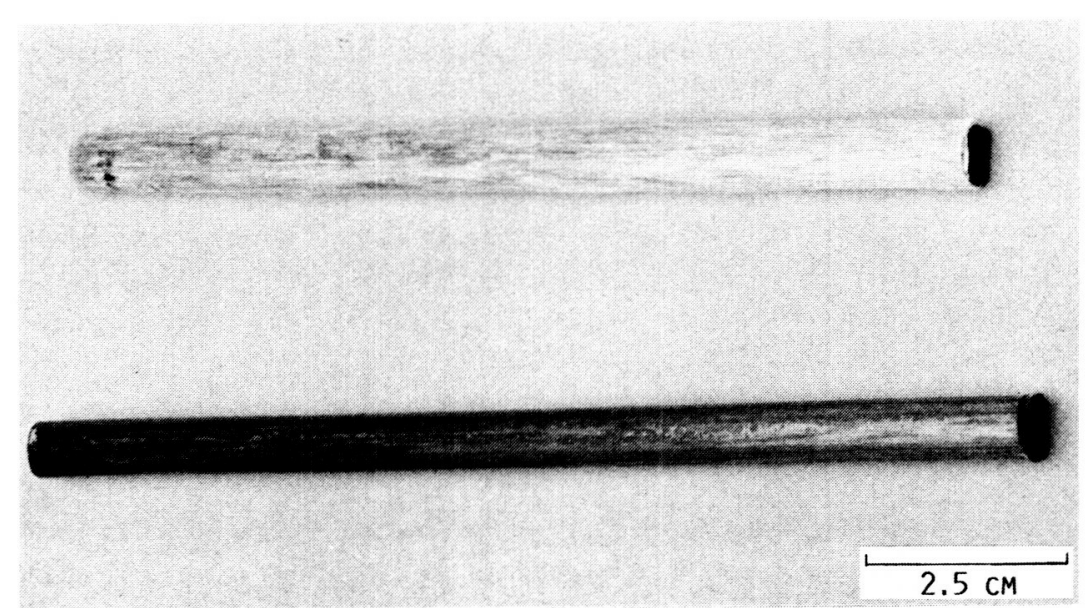

FIGURE 6. - LONG DURATION ASHED SAMPLE (TOP) VERSUS CONTROL SAMPLE (BOTTOM). 


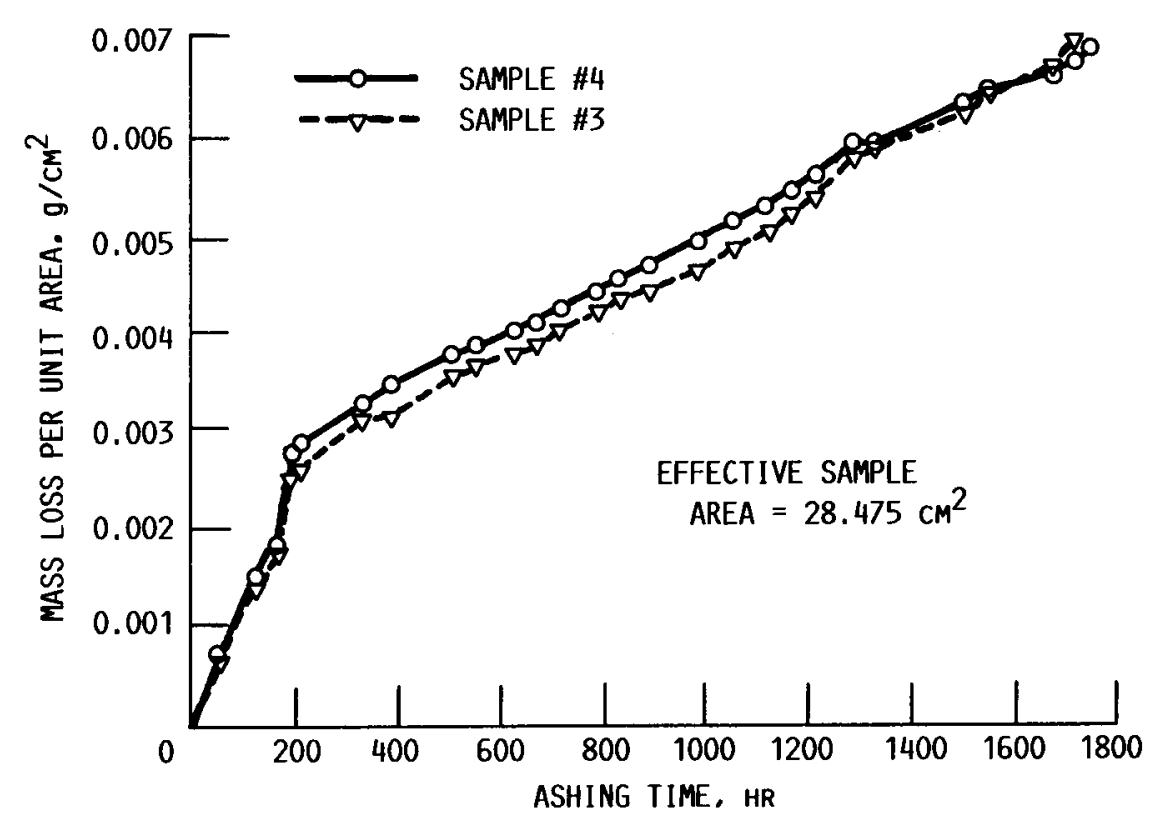

FIGURE 7. - STANDARIZED MASS LOSS CURVE IN AIR PLASMA ASHER FOR UNPROTECTED SAMPLES.

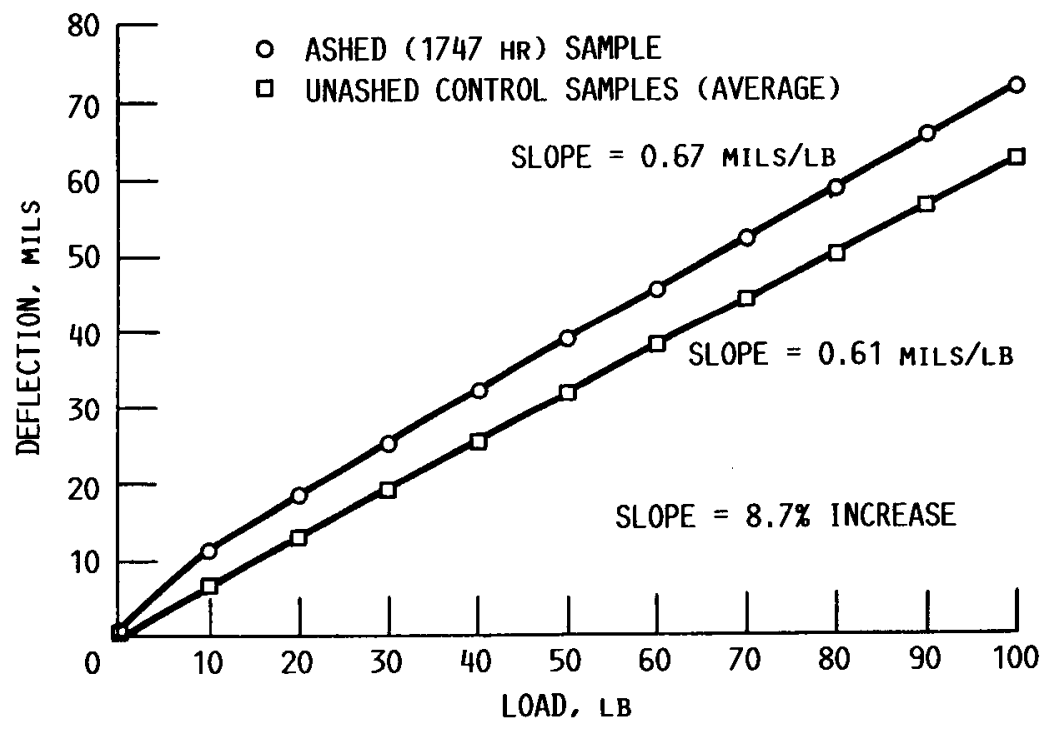

FIGURE 8. - LOAD-DEFLECTION CURVES FOR LONG-DURATION ASHED AND CONTROL SAMPLES. 


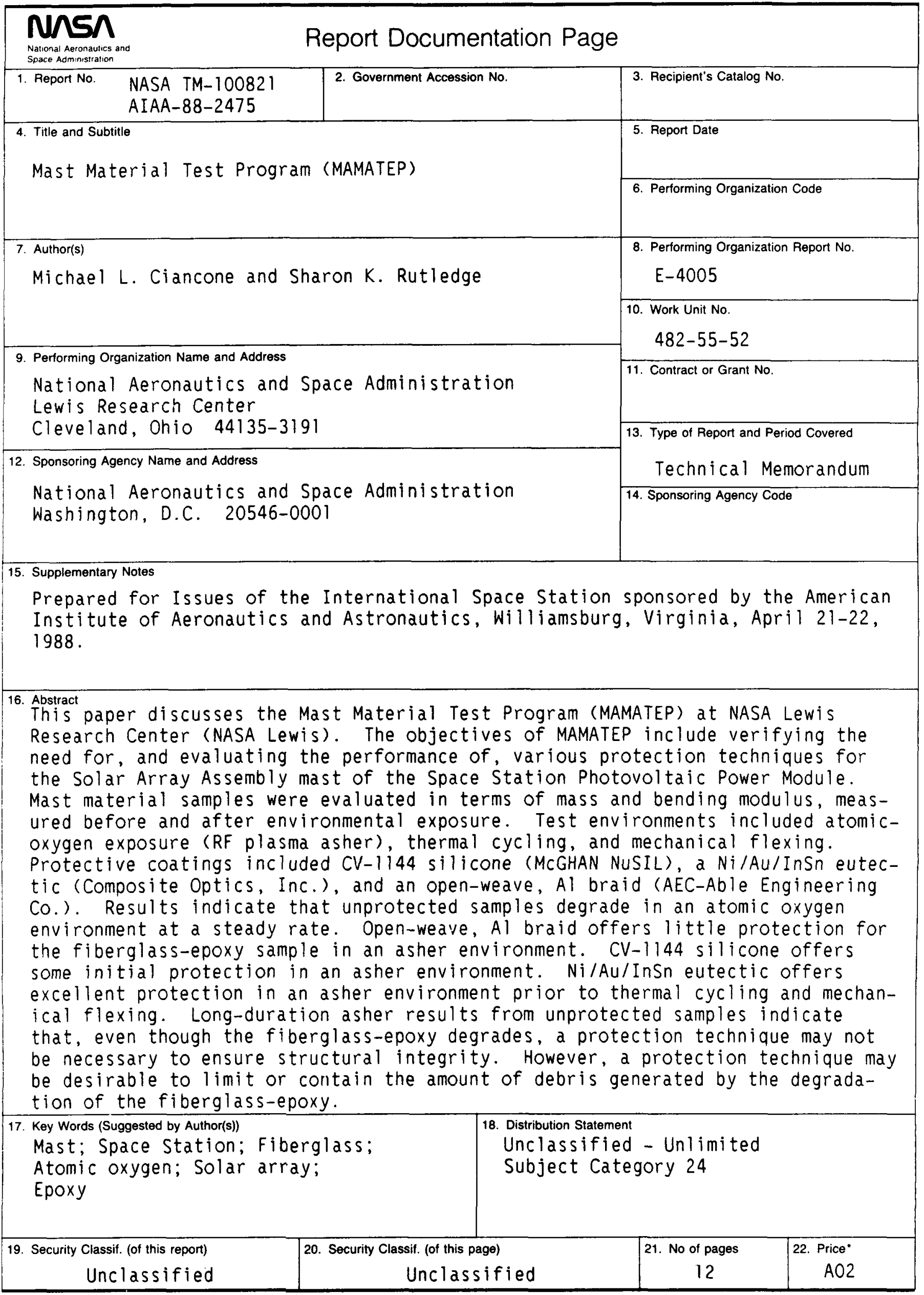

